Hispania Sacra, LXV

\title{
DEVOCIÓN Y RELIGIOSIDAD DE UN LINAJE JUDEOCONVERSO: LA FAMILIA CORONEL
}

\author{
POR \\ EFRÉN DE LA PEÑA BARROSO \\ Cuerpo Facultativo de Archiveros, Bibliotecarios y Arqueólogos
}

\begin{abstract}
RESUMEN: El estatus nobiliario recientemente adquirido por algunos de los miembros de las familias judeoconversas castellanas de finales del siglo XV provocó que la estética refinada y el gusto por el lujo se incorporasen a sus prácticas religiosas cotidianas. Algunas de estas familias invirtieron grandes fortunas en la fundación de capillas y en la dotación económica de determinados templos cristianos. La familia segoviana Coronel, recién llegada a la hidalguía, se unió a esta tendencia de perpetuación del linaje cuando fundó y dotó una hermosa capilla en el monasterio de Santa María del Parral, que a la postre habría de convertirse en panteón familiar.
\end{abstract}

PALABRAS CLAVE: Coronel; linajes; conversos; capillas; testamentos; religiosidad; Castilla; siglo XV.

\section{DEVOTION AND CHRISTIAN PRACTICES OF A "CONVERSO" LINEAGE: THE CORONEL FAMILY}

ABSTRACT: The brand new noble status of some of the members of the Castilian "converso" families at the end of the $15^{\text {th }}$ Century combined their daily religious practices with noble customs and aesthetics. Some of these families spent large amounts of money in erecting chapels and in donating funds to a wide variety of Christian institutions. The Segovian Coronel family had recently been rewarded as noblemen of the lowest grade and joined this tendency of lineage reinforcement by founding and donating money to a beautiful chapel in the Monastery of Santa María del Parral, which finally became the family vault.

KEY WORDS: Coronel; lineages; conversos; chapels; testaments; religiousness; Castile; 15th Century. 
Recibido/Recibido

$16-02-2011$

Acetado/Accepted

$16-02-2013$

\section{INTRODUCCIÓN}

Desde los inicios del siglo XV los monarcas castellanos y la nobleza utilizaron las representaciones ceremoniales, simbólicas e iconográficas como un eficaz método de propaganda social para su perdurabilidad en el recuerdo colectivo. Entre estas manifestaciones de exaltación del linaje ocupó un lugar destacado la espiritualidad practicada por los miembros de las familias, que fue empleada para "asociar la memoria del linaje con lo sagrado". ${ }^{1}$ Esta vinculación llegaba a su clímax cuando el individuo fallecía. Era entonces cuando entraba en juego la plasticidad visual de las exequias y del sepulcro, que habían de ser lo suficientemente impactantes como para quedar grabados en la retina de los vivos. Entre otras formas de religiosidad, los fastos fúnebres debían reflejar el estatus social que el individuo había ostentado en vida, ya que estaban considerados como una forma de revalidar post mortem las jerarquías y los valores sociales. ${ }^{2}$ De ahí la importancia que tuvo en la época la construcción de esplendorosos sepulcros y de suntuosas capillas funerarias.

Efectivamente, la elección de un espacio religioso determinado como panteón familiar tenía como objetivo la perpetuación del apellido en ese lugar, además de otorgar a la institución que lo albergaba mayor prestigio y considerables beneficios materiales. ${ }^{3}$ Con ello, las comunidades religiosas asociadas al lugar elegido para ubicar el panteón quedaban estrechamente vinculadas al su fundador y a su descendencia no sólo en cuestiones de culto, sino también en numerosos asuntos políticos en los que los frailes desempeñaron misiones de distinta índole. ${ }^{4}$

Las familias judeoconversas de renombre de la Castilla de finales del siglo XV no fueron ajenas a estas tendencias, si bien tuvieron que soportar además el peso de las sospechas relativas a la calidad de su conversión. Por eso necesitaron de un mayor esfuerzo para demostrar la sinceridad de sus creencias cristianas y para conseguir acabar con los rumores sobre su criptojudaísmo. El auge económico de muchas de ellas

1 Carrasco Martínez, A. 2000. "Los Mendoza y lo sagrado. Piedad y símbolo religioso en la cultura nobiliaria". Cuadernos de Historia Moderna 25: 233.

2 Ladero Quesada, M.A. 1998. Los señores de Andalucía. Investigaciones sobre nobles y señoríos en los siglos XIII a XV: 37 Cádiz: Universidad de Cádiz.

3 Ortego Rico, P. 2008. "El patrocinio religioso de los Mendoza: siglos XIV y XV". En la España Medieval 31: 302.

4 Carrasco Martínez, A. 2000: 237 y 242. 
y la intensa actividad inquisitorial de finales de siglo determinaron la fundación de un gran número de estas capillas familiares en distintas parroquias y monasterios. ${ }^{5}$

Este es el caso de la familia segoviana Coronel, que a través de la fundación de una capilla, de su dotación y de las piadosas mandas testamentarias de sus miembros, intentó eliminar cualquier rastro de su ascendencia judía. Su particular devoción cristiana culminó con el ingreso en convento de una bisnieta de Fernán Pérez Coronel.

\section{LA FUNDACIÓN DE LA CAPILLA}

Los Reyes Católicos actuaron como padrinos en el bautismo de Abraham Seneor el 15 de junio de 1492, quien recibió el nombre de Fernán Pérez Coronel. Los monarcas le concedieron el antiguo linaje Coronel, de probado abolengo y ya en desuso, y una hidalguía perpetuable en sus sucesores. ${ }^{6}$ Desde ese momento, el fundador se inició en las manifestaciones públicas de religiosidad y piedad cristianas. Por eso, como contaba con aproximadamente 80 años, Fernán Pérez Coronel aprovechó la reciente construcción del monasterio de Santa María del Parral de Segovia para fundar y dotar allí una capilla. Con esta fundación probablemente intentaba borrar sus orígenes judíos, reafirmar sus nuevas creencias cristianas, vincular su linaje con un centro religioso de primer orden en la ciudad de Segovia y alcanzar honra, fama y prestigio que pudiesen ser transmitidos y acrecentados por sus herederos y sucesores. ${ }^{7}$

El monasterio jerónimo de Santa María del Parral se encontraba en el paraje conocido como la Alameda, a los pies de las denominadas "Peñas Grajeras" y asomado al río Eresma. Fue llamado así porque en su emplazamiento había a comienzos del siglo XV una ermita en la que se rendía culto a Santa María y que se denominaba Nuestra Señora del Parral porque estaba cubierta por una parra antigua. El marqués de Villena compró los terrenos en el año 1447 y poco después obtuvo la correspondiente bula pontificia para comenzar a edificar la iglesia. Sin embargo, la construcción del resto del monasterio corrió a cargo de

5 Gómez-Menor Fuentes, J.C. 1970. Cristianos nuevos y mercaderes de Toledo: 59 Toledo: Zocodover.

${ }^{6}$ Esta excepcional circunstancia ha sido estudiada por Ladero Quesada, M.A. 2003. "Coronel, 1492: de la aristocracia judía a la nobleza cristiana en la España de los Reyes Católicos". Boletín de la Real Academia de la Historia 200/1: $11-24$.

7 En la misma línea había actuado Diego Arias Dávila al fundar en Segovia el Hospital de San Antonio. Véase Rábade Obradó, M.P. 2002. "Mecenazgo religioso y estrategias familiares en la Segovia del siglo XV: Diego Arias Dávila y el Hospital de San Antonio". Anuario de Estudios Medievales 32/2: 918-919. 
Enrique IV que, muy devoto de San Jerónimo, lo encomendó a esta orden. El establecimiento terminó de edificarse en el año 1503.

No parece que la elección de fundar la capilla familiar en un monasterio jerónimo fuese casual. La conversión al cristianismo de Fernán Pérez Coronel también se había producido en Nuestra Señora de Guadalupe, monasterio cacereño de la misma orden. El carácter modélico de los jerónimos en cuanto a su forma de vida religiosa (retiro, humildad, contemplación sin excesivo intelectualismo y autosuficiencia económica) provocó que los distintos monarcas castellanos tuviesen predilección por sus establecimientos, lo que otorgó a sus casas un prestigio extraordinario que muchos conversos utilizaron para disimular sus orígenes. La ausencia de estatutos de limpieza de sangre en la orden invitó a un buen número de conversos a ingresar en sus claustros como frailes, ${ }^{8}$ lo que a la vez convirtió estos monasterios en focos de judaizantes que los tribunales inquisitoriales investigaron con rigor. ${ }^{9}$

La capilla fundada por Fernán Pérez Coronel, denominada "Capilla del Descendimiento" o "del Crucifijo", situada en el lado del Evangelio, es la segunda por la izquierda desde los pies de la iglesia. Su orientación al norte hace que la luz sea tenue en las horas centrales del día y que los agresivos efectos de la humedad desluzcan sus muros en la actualidad.

La portada de la capilla, labrada en piedra caliza blanca tan abundante en la zona, se remata por un arco rebajado y trasdosado por un arco conopial. En la clave del arco se colocó el escudo de armas de la familia, del que actualmente tan solo se conserva la mitad superior. La nervadura de las bóvedas estrelladas nace de ménsulas rematadas por ángeles portadores de las mismas armas. En las paredes interiores de la capilla se conservan tres lucillos que debieron albergar los sepulcros de la familia Coronel. En el muro norte, una hornacina vacía señala el lugar en el que se ubicaba el retablo de talla. ${ }^{10}$

Las riquezas que Fernán Pérez Coronel amasó durante sus últimos años de vida fueron el respaldo indispensable de su linaje y a la vez le permitieron dotar suficientemente su capilla. De hecho, los ornamentos litúrgicos y las rentas eran dos requisitos imprescindibles que el patrono debía aportar para realizar una fundación en una determinada institución

8 El Capítulo General decretó en el año 1486 la prohibición de admitir a conversos en la orden, decisión que provocó la división de los frailes. En el año 1495 el estatuto de exclusión fue confirmado definitivamente. En Domínguez Ortíz, A. 1991 (1 $1^{\mathrm{a}}$ ed. 1955). La clase social de los conversos en Castilla en la Edad Moderna: 67 Granada: Universidad de Granada (edición facsímil).

9 Para el caso de Guadalupe, los peculiares comportamientos de los monjes jerónimos conversos y de sus prácticas judaizantes han sido bien estudiados por Evans, J.A. 1998. Heresy as an agent of change. Inquisition in the Monastery of Guadalupe. Stanford University (tesis doctoral inédita).

${ }^{10}$ La descripción de los elementos arquitectónicos de la capilla la hemos extraído de la página web del Monasterio, disponible en el siguiente enlace:

http://www3.planalfa.es/msmparral/parral/fondo.htm 
religiosa. ${ }^{11}$ Así, Fernán Pérez Coronel la dotó con una renta anual de 10.000 maravedíes "por juro de heredad" para que se rogase por su alma. ${ }^{12}$ Sus hijos íñigo López Coronel y Juan Pérez Coronel se encargaron del pago de esa renta ${ }^{13} \mathrm{y}$ además donaron al monasterio algunos bienes, rentas y heredamientos en diversos lugares de su entorno: en las tercias de Zamarramala y Olavarrus (paraje sin localizar) le correspondían 1.500 maravedíes, y en las tercias de Santa Olalla y de la Veracruz otros 1.000. Esos 2.500 maravedíes habían sido donados "para en pago de los diez mill maravedís de juro que mandó Hernando Pérez Coronel para dote de su capilla, padre de los sobredichos". ${ }^{14}$ Los 7.500 restantes se pagaron en metálico y con distintas heredades. Así fue como el monasterio obtuvo una heredad que rendía 55 fanegas de pan mediado en término de Zamarramala, a las afueras de Segovia. ${ }^{15}$ Esta tierra fue recibida por los monjes jerónimos

"en pago de los ciento diez mil [maravedíes] que íñigo López Coronel era obligado a pagar de los diez mil de juro que mandó Hernand Pérez Coronel, su padre, para dote de su capilla. Y no tenía juro, y tasose su parte en los dichos ciento y diez mil con cierta parte que pagó por sus sobrinos, hijos de Juan Pérez de la primera mujer, y así dio la dicha heredad tasada como dicho es". ${ }^{16}$

Pero Fernán Pérez Coronel no sólo se ocupó de los aspectos arquitectónicos de la capilla. También ordenó hacer su retablo y donó para ornamento de la estancia y mayor dignidad del culto divino "un

11 Ortego Rico, P. 2008: 298.

12 Por Fernán Pérez Coronel y sus descendientes se decían cada año 100 misas "ad libitum", a razón de dos misas cada semana. En Hernández Ruiz de Villa, R. 1966. "El libro del monasterio de Santa María del Parral de Segovia. Transcripción y notas". Estudios Segovianos 18: 329. Agradezco a Juan Manuel Moreno Yuste, Coordinador de Publicaciones de la Academia de San Quirce de Segovia, que me remitiese amablemente un ejemplar de este extenso artículo.

${ }^{13}$ La genealogía de la familia puede verse en Peñalosa, L.F. 1949. "Juan Bravo y la familia Coronel". Estudios Segovianos 1: 93-97; y en Carrete Parrondo, C. 1986. "R. Abraham Seneor (Fernán Pérez Coronel): conjeturas tradicionales y realidad documental". Sefarad 46: 111-122.

14 Hernández Ruiz de Villa, R. 1966: 307-308.

15 Entre la documentación de la familia Coronel se ha conservado la compra judicial realizada por Juan Moreno el 21 de agosto de 1491 de "media çerca, e dos casas caýdas pequeñas, e dos solares pequeños" situados en Zamarramala, por precio de 7.000 maravedíes. Estas propiedades habían pertenecido a Alonso González Correviernes, condenado por hereje el año anterior, y por motivos aún desconocidos acabaron entre los bienes de la familia Coronel. Archivo Histórico de la Nobleza (en adelante, AHNob), VIVERO, C.1, D.1.

16 Hernández Ruiz de Villa, R. 1966: 222-323. 
frontal de brocado, que se dice picholado, con dos piernas de seda rasa morada porque era corto, a los lados guarnescido". ${ }^{17}$ El fundador entregó además algunas ropas talares como "una casulla de colcha de zarzabán ${ }^{18}$ con su alba, stola y manípulo guarnescida; otra casulla de seda rasa morada que tiene una çanefa de seda verde rasa, con su aparejo". ${ }^{19}$ También donó "otro cálice mediano blanco y dorada la copa de dentro y el bebedero y algunas cosas en el pie, con sus armas debaxo". ${ }^{20}$

A esto habría que añadir lo entregado por sus hijos, que dieron "un paño grande de tres anchos de seda verde azeituní ${ }^{21}$ con una cortapisa de seda morada de pelo y enforrado para su sepultura". ${ }^{22}$ Fallecido Juan Pérez Coronel, fue su hijo del mismo nombre, apodado "el mozo", quien se encargó de pagar lo que le cabía del juro de Fernán Pérez Coronel. Sin embargo, como "el mozo" no tenía ningún juro en propiedad, pagó su mitad con 2.118 maravedíes "que paga cada año y no están situados". ${ }^{23}$ Además, su esposa "dio un brial de terciopelo verde de que se hizo una saya para Nuestra Señora. E de lo que sobró se hicieron faldones de alvas". ${ }^{24}$

No podemos perder de vista la dimensión social que en aquella época conllevaba el gasto en obras pías, que se traducía en la mayor admiración a su fundador y en el mejor recuerdo de los suyos. Por eso los descendientes de Fernán Pérez Coronel se implicaron personalmente en el mantenimiento de su memoria ya que, como ha sido señalado, la nueva religiosidad conversa perseguía "sacralizar las fortunas" que se habían conseguido en vida a la vez que dar buena prueba de la sinceridad de sus nuevas creencias cristianas. ${ }^{25}$

Es más que probable que Fernán Pérez Coronel mandase que le enterraran en la capilla que había fundado. ${ }^{26}$ Al fin y al cabo, los

17 Ibídem, 359.

${ }^{18}$ Por zarzahán: fino tejido de seda con listas de colores que a veces era bordado con oro. En Martínez Meléndez, M.C. 1989. Los nombres de tejidos en castellano medieval: 376-378. Granada: Universidad de Granada.

19 Hernández Ruiz de Villa, R. 1966: 359.

20 Ibídem, 373.

21 Tejido de seda teñida parecido al terciopelo y que podía también bordarse con oro. En Martínez Meléndez, M.C. 1989: 241-246.

22 Hernández Ruiz de Villa, R. 1966: 359.

23 Ibídem, 329.

24 Ibídem, 359.

25 Gómez-Menor Fuentes, J.C. 1970: L-LI.

${ }^{26}$ El historiador decimonónico José María Cuadrado apuntó que Fernán Pérez Coronel estuvo enterrado en la iglesia de Santa Cruz de Segovia, en una capilla llamada "de la Santa Cueva" o "Cueva de Santo Domingo". El rey Felipe II, al saber que había allí un sepulcro de un miembro de la familia Coronel, lo mandó quitar diciendo: "Aún para mí sería éste un lugar demasiado digno". Citado por García Casar, M.F. 2005. "Nuevas noticias sobre los SeneorCoronel segovianos", en Y. Moreno Koch y R. Izquierdo Benito (coords.), Del pasado judío en los reinos medievales hispánicos. Afinidad y distanciamiento: 
fundadores erigían las diferentes capillas para sí mismos y sus sucesores, y supervisaban los trabajos de su construcción para asegurarse de que tendrían una sepultura acorde a su nueva posición social. ${ }^{27}$ Como veremos en el caso de la familia Coronel, algunos de sus miembros también dispusieron que sus enterramientos se realizasen allí, por lo que la nueva capilla acabó por convertirse en panteón familiar.

\section{LA DEVOCIÓN DE ÎNIIGO LÓPEZ CORONEL}

La participación de íñigo López Coronel en el movimiento comunero y la previsible represión política que había de realizar el bando vencedor motivaron que este hijo de Fernán Pérez Coronel abandonase la ciudad de Segovia una vez que las tropas del emperador derrotasen a los insurgentes en la batalla de Villalar. Se desconocen los motivos por los que Íñigo López Coronel eligió la villa sevillana de Osuna como destino de su exilio, pero todo apunta a que debió buscar la protección de don Pedro Girón, que también había tomado parte en la revolución comunera, instalándose en territorios de su jurisdicción. Sin embargo, pocos meses después de su llegada a esta villa y apenas repuesto de su azarosa aventura, el regidor segoviano tuvo que otorgar testamento apresuradamente el 29 de marzo de 1522 porque su vida se agotaba. ${ }^{28}$ En él dispuso que su cuerpo fuese depositado en la Colegiata de Santa María de la Asunción de Osuna hasta que se trasladase y enterrase en la capilla fundada por su padre en el monasterio de Santa María del Parral.

Mandó además que se dijesen trece misas "de la luz" y cinco "a las çinco plagas", y tres más "a onor e reverençia de la Santísima Trenidad". $Y$ que en la villa de Osuna le diesen "dos treyntanarios de misas çerrados". ${ }^{29}$ También dejó repartidas ciertas cantidades de dinero para las órdenes religiosas encargadas de la redención de cristianos cautivos (mercedarios y trinitarios), además de otras limosnas a distintas instituciones sevillanas como el hospital de San Lázaro, las casas de San Antón y Santa María de la Sed y otras iglesias, ermitas y cofradías de la ciudad que no se citan.

Cuenca, Universidad de Castilla-La Mancha. El programa iconográfico de dicha capilla, cargado de alusiones a la Inquisición y a la persecución de la "herética pravedad", establece esta opción como poco probable. Véase el artículo de Carrero Santamaría, E. 2001. "Patrocinio regio e Inquisición. El programa iconográfico de la Cueva de Santo Domingo, en Santa Cruz la Real de Segovia", en Actas del Congreso Internacional sobre Gil Siloe y la Escultura de su época: 452-462. Burgos: Institución Fernán González y Academia Burgense de Historia y Bellas Artes.

27 Carlé, M.C. 1993. Una sociedad del siglo XV: los castellanos en sus testamentos: 119 [Buenos Aires]: Instituto de Historia de España.

${ }^{28}$ Una copia del testamento se conserva en AHNob, VIVERO, C.17, D.5.

${ }^{29}$ Ibídem, fol. 3v. 
Una vez resuelto su lugar de enterramiento y el reparto de sus mandas piadosas, íñigo López Coronel dispuso la dotación a tres miembros de su servicio con cantidades muy considerables: a Juan de Córdoba, su criado, y a Pedro Ruiz de la Peña les dejó 100.000 maravedíes a cada uno, mientras que a Alonso de Peñalosa, a quien llamaba "su mochacho", le dejó 10.000 maravedíes. ${ }^{30}$ Se ha sugerido que estas abultadas cantidades enmascaraban posibles relaciones clientelares a través de un mecanismo de gratificación y de control, ${ }^{31}$ a la vez que reflejaban la hegemonía social y económica alcanzada por el patrono. Los criados realizaban importantes servicios domésticos y administrativos a sus dueños, en ocasiones como mayordomos y contadores, con lo que se justificaban así los legados testamentarios que se les realizaban. ${ }^{32}$ Por último, mandó dar a Juana González, "su casera", tres reales, lo que podría indicar que la vivienda en la que se había alojado en Osuna era alquilada.

Pero quien verdaderamente gozó de los bienes de íñigo López Coronel fue su hija María Coronel. Aunque también dejó parte de su herencia a Leonor, su otra hija, a María le dejó "el terçio e el remaniente del quinto de sus bienes, el qual dicho terçio e remaniente del quinto aya e lieve de mejoría de sus bienes más que la otra su fija e heredera", y además la cantidad de 120.000 maravedíes de juro en la recaudación del "servicio y montazgo". ${ }^{33}$

Los enseres personales que íñigo López Coronel dejó en Osuna al morir reflejan la austeridad de un hombre que había tenido que salir apresuradamente de su ciudad. ${ }^{34}$ En el inventario de bienes de su morada sevillana destacan los pertrechos utilizados para su viaje (maletas y alforjas) y otros tantos que la cotidianidad requería (esteras y colchones), como la poca ropa de vestir que tenía, casi toda ella ya traída y de un triste color negro (camisas, sayos y calzones); la ropa de cama y del hogar igualmente vieja (manteles, sábanas y almohadas), aunque fabricada de algunos tejidos importados y comercializados en las importantes ferias de Medina del Campo (ruanes, sedas, holandas y alemaniscos); una mula y una acémila de carga; ${ }^{35}$ un ejemplar de la novela de tema caballeresco titulada Oliveros de Castilla y Artús de

${ }^{30}$ Ibídem, fol. $3 r$.

31 Ortego Rico, P. 2008: 277; y Jara Fuente, J.A. 1996. "Muerte, ceremonial y ritual funerario: procesos de cohesión intraestamental y de control social en la alta aristocracia del Antiguo Régimen (Corona de Castilla, siglos XV-XVIII)". Hispania 194: 876.

${ }^{32}$ Carlé, M.C. 1993: 147. Y, de la misma autora, 1988. "La sociedad castellana del siglo XV en sus testamentos". Anuario de Estudios Medievales 18: 539-540.

33 AHNob, VIVERO, C.17, D.5, fol. 4r.

34 Ibídem: fols. 4v y ss. El inventario está transcrito en el Apéndice I.

${ }^{35}$ La acémila fue vendida a Pedro Belmonte por precio de diez ducados. Ibídem, fol. $6 r$. 
Algarve ${ }^{36}$ una espada "desguarneçida" y un repostero de lana con un escudo "con çinco águilas". ${ }^{37}$ No hay que olvidar que los escudos nobiliarios eran la expresión visual del linaje, y como tal se ostentaban sobre el cuerpo, las fachadas de las casas, los tapices que adornaban las paredes de las mismas y, por supuesto, en las capillas y sepulturas donde reposaban los miembros del linaje. ${ }^{38}$

\section{LAS OBRAS DE MANTENIMIENTO DE LA CAPILLA}

La capilla familiar no estuvo exenta de reparaciones y de reformas más profundas. Al fin y al cabo, habían pasado más de veinte años desde que se enterrase allí su fundador y la estancia se había deteriorado seguramente por los efectos de la humedad. Fue doña María Coronel, que había casado con íñigo López Coronel en fecha aún desconocida, quien se ocupó de estas obras de mantenimiento.

En estas circunstancias, la familia Heredia apareció en escena. La capilla de esta familia, adosada a la de los Coronel, debió de ser la última que se edificó en la iglesia. La disposición en línea de las capillas hacía que cualquier modificación en una de ellas afectase a las inmediatamente contiguas. Por eso, en 1516 los intereses de doña María Coronel chocaron con los de Isabel de Heredia, propietaria de la capilla de la Natividad. En esa fecha las dos señoras acordaron construir un muro medianero entre ambas estancias. Para ello pidieron consejo a Juan de Ayala y a García de la Lombana, maestros canteros nombrados por ambas señoras, respectivamente, "sobre la lavor de las capillas que

${ }^{36}$ Esta obra era una adaptación al castellano de una novela francesa anterior escrita por Philippe Camus a mediados del siglo XV. La primera edición en castellano se publicó en Burgos en 1499, y la siguieron otras muchas durante el comienzo del siglo XVI. La obra tuvo mucho éxito a lo largo de todo ese siglo. Para acercarse a la difusión que gozó el libro puede verse el artículo de Frontón, M.A. 1989. "La difusión del Oliveros de Castilla: apuntes para la historia editorial de una historia caballeresca". Dicenda. Cuadernos de Filología Hispánica 8: 37-51; y para ver la adaptación al castellano del texto francés, el artículo del mismo autor 1989. "Del Olivier de Castille al Oliveros de Castilla: análisis de una adaptación caballeresca". Criticón 46: 63-76.

37 El escudo heráldico de la familia Coronel se componía de cinco aguilones en sotuer sobre campo de gules, aunque algunos pintaron el campo de azur y las águilas de oro. En García Carraffa, A. y A. 1955. Diccionario heráldico y genealógico de apellidos españoles y americanos. vol. 25: 187 Madrid. Blas de Salazar lo reprodujo en campo de oro, con cinco cornejas o cuervos negros (en AHNob, TORRELAGUNA, C.231, D.2, fol. 213r); y otro heraldista anónimo en campo colorado, con cinco águilas blancas (en AHNob, TORRELAGUNA, C.435, D.1, fol. 137v). Para las dos últimas representaciones, véase el Apéndice II. Otra representación de este escudo la ha publicado Ladero Quesada, M.A. 2003: 16.

38 Carlé, M.C. 1993: 164. 
tienen en el dicho monesterio del Parral". ${ }^{39}$ Los dos canteros, después del debate mantenido por las propietarias, determinaron que la pared medianera que separaba las dos capillas debía de ser alzada. Pensaban a su vez que aunque se cegase la ventana que se estaba construyendo en dicha pared todavía quedaría suficiente luz en el interior de cada estancia. También acordaron que los pilares del arco principal que dividía ambos recintos fuesen "asentados e sobidos fasta capiteles", además de que este arco estuviese "bien aforrado en la coz [...] de la una parte e de la otra". ${ }^{40}$ Por último, convinieron que la nueva pared divisoria debía dejarse reposar "algunos días fasta que la cal esté enxuta e fraguada". Cuando se consolidase este muro se procedería a derribar la pared vieja.

Una vez finalizadas las obras y devuelta la vistosidad a la sala, el panteón estaba listo para albergar a otros miembros de la familia. De hecho, doña María Coronel dispuso en su testamento que su cadáver también fuese enterrado en esta capilla junto al de su esposo, ${ }^{42}$ lo que no era sino una expresión de la perdurabilidad de los afectos más allá de la muerte. ${ }^{43}$ Para sus exequias dejó dicho

"que lleven quatro carneros, e quatro reses de toro, e quatro cántaras de vino, e çinco hachas a onor y reverençia de las çinco plagas que nuestro señor Ihesu Christo reçibió en su cuerpo por nosotros pecadores salvar, e que las lleven çinco pobres a los quales den sendas ropas de paño azul trezeno" ${ }^{44}$

También ordenó que el día de su enterramiento los frailes del monasterio dijesen cinco misas de requiem y que, desde ese día hasta la novena, le dijesen otra misa diaria, para lo cual dispuso que se diese a los monjes "cada día un cuartal de pan e un cuartillo de vino, e que por ello paguen los dineros acostunbrados". ${ }^{45}$ Además, mandó que desde el día de la novena hasta el final del año se dijese una misa al día en dicha capilla, "e salga el preste que la dixere e diga un responso sobre mi sepultura, e por ello les paguen los dineros acostunbrados".

Las limosnas que concedió a las órdenes de mercedarios y trinitarios fueron de cinco maravedíes a cada una, "a onor y reverençia

39 AHNob, VIVERO, C.17, D.3, fol. 2r. Fechado el 14 de junio de 1516. El documento recoge el acuerdo al que llegaron los dos canteros.

40 ídem.

${ }^{41}$ Ibídem: fol. 2v.

${ }^{42}$ El testamento fue otorgado en Segovia el 22 de junio de 1522. En AHNob, VIVERO, C.17, D.6. En el testamento de Leonor Coronel, su hija, otorgado el 11 de julio de 1522, doña María Coronel ya aparece como fallecida, por lo que debió morir en ese ínterin.

${ }^{43}$ Carlé, M.C. 1993: 119.

${ }^{44}$ AHNob, VIVERO, C.17, D.6, fol. 2r.

${ }^{45} \mathrm{Ibídem}$, fol. 2v. Las siguientes frases en cursiva pertenecen al mismo folio. 
de las çinco plagas que nuestro señor Ihesu Christo reçibió en su sacratísimo cuerpo por nosotros pecadores salvar". Y en un gesto de caridad cristiana, mandó liberar a Francisco, a Leonor y a su hijo Pedro García, y a otro Francisco, sus criados y esclavos, y les donó las camas, ropas y vestidos que normalmente utilizaban.

Por último, dejó por sus albaceas testamentarios a maestre Pablo, a doña María y a doña Leonor, sus hijas, y por universales herederas a estas últimas, ratificando a María Coronel en el tercio y quinto de los bienes que había dejado îñigo López Coronel.

\section{LOS TESTAMENTOS DE LEONOR Y MARÍA CORONEL}

Una de las hijas de íñigo López Coronel y de doña María Coronel se llamó Leonor Coronel. Apenas se conocen datos sobre su vida, salvo que su padre se comprometió a que ingresase en convento. De todos modos debió morir aún doncella pocos días después de otorgar testamento en Segovia el 11 de julio de $1522 .^{46}$

Leonor Coronel también pidió ser sepultada en la capilla familiar fundada por su abuelo. Después mandó que se dijesen en el monasterio diez misas por ella, además de realizar las habituales ofrendas de pan, vino e incienso. Por último, entregó a cada una de las órdenes liberadoras de cautivos la cantidad de cinco maravedíes.

En cuanto a las donaciones, Leonor Coronel dejó algunos ropajes a mujeres de su entorno más cercano para que rogasen por su alma: a Bobadilla, su ama, acaso emparentada con los marqueses de Moya, le dio la mejor de sus sayas, un sayuelo y su hábito. ${ }^{47}$ A Elvira Hernández le dejó una saya que había pertenecido a su madre, un manto y una saya de la testadora. Y a Leonor Fernández le dejó una saya blanca y un sayuelo suyos, y otra saya de Frisia de su madre. Para cumplir todo lo contenido en su testamento Leonor Coronel nombró como sus albaceas a María Coronel, su hermana, y a maestre Pablo Coronel, y dejó por universal heredera a su hermana María.

Otra de las hijas de íñigo López Coronel y de doña María Coronel recibió el mismo nombre que su madre. No sabemos la fecha de su nacimiento, pero podemos aventurar que residió en Segovia durante la mayor parte de su vida. María Coronel fue heredera única tanto de sus padres como de su hermana $y$, como tal, dispuso de un enorme patrimonio que le permitió estrechar aún más el vínculo de la familia con los frailes jerónimos del monasterio del Parral. De este modo, donó al monasterio 102.000 maravedíes para que se comprasen 3.000

46 Puede verse en AHNob, VIVERO, C.17, D.7.

47 Los progenitores que tenían medios económicos suficientes solían confiar a alguno de sus hijos a otras familias mejor colocadas socialmente para que los criasen y pudiesen tener más oportunidades que las ofrecidas por su propia familia. En Carlé, M.C. 1993: 138. 
maravedíes de juro para dotar las fiestas religiosas de la Asunción y de Todos los Santos: la primera se celebró desde entonces con una misa cantada infra octava en el altar mayor y una misa rezada en la capilla de la familia, para terminar con un responso también en dicha estancia. Para la celebración de la fiesta de los Santos dispuso que se ofreciesen dos fanegas de trigo y media cántara de vino, que se encendiesen dos hachas en su capilla y que se dijese una misa rezada por ella y por sus difuntos, además de un responso cantado en dicho lugar. ${ }^{48}$

Uno de los hechos más relevantes en la vida de María Coronel fue que en el año 1519 contrajo matrimonio con Juan Bravo, futuro capitán de la "comunidad" de Segovia. Este matrimonio otorgó mayor prestigio a la familia Coronel y un entronque con la alta nobleza de Castilla, ya que Juan Bravo pertenecía a la familia Mendoza por vía materna. ${ }^{49}$ De este matrimonio nacieron Juan y Andrea Bravo de Mendoza, que quedaron huérfanos de padre después de su ejecución el 24 de abril de 1521. María Coronel casó hacia 1525 en segundas nupcias con Fadrique de Solís, ${ }^{50}$ con quien tuvo otros dos hijos llamados Íñigo y Antonio de Solís, menores de edad cuando su madre testó. ${ }^{51}$

Estas notas genealógicas resultan muy útiles para entender el testamento de María Coronel, otorgado el 28 de noviembre de 1528 en sus casas de Bernardos (Segovia). ${ }^{52}$ No obstante, sobrevivió hasta el mes de octubre del año 1550, fecha en que se menciona a esta dueña como recién fallecida y se realizó la partición de su herencia. Sea como fuere, y al igual que hicieran sus progenitores, María Coronel pidió ser enterrada en el monasterio del Parral, en la capilla fundada por Fernán Pérez Coronel, su abuelo, y junto a la tumba de su madre.

También pidió que el día de su enterramiento se dijesen 30 misas de requiem en el monasterio, y que se diese por ofrenda "quatro hanegas de trigo y dos cántaras de vyno y quatro carneros". ${ }^{53}$ Ordenó además que se rezase una novena y que se ofreciese al monasterio "un quartal de

48 Hernández Ruiz de Villa, R. 1966: 359-360.

49 Peñalosa, L.F. 1949: 81. Otros autores han insistido en la idea de que los conversos castellanos pusieron "verdadero empeño en contraer vínculos familiares con los cristianos viejos", sobre todo los que poseían riquezas, ya que "el oro les sirvió de señuelo para emparentar incluso con las más altas casas". En Domínguez Ortíz, A. 1955: 151.

${ }^{50}$ Fadrique de Solís era hijo del doctor Dionisio de Solís y de Felipa de Solís, vecinos de Segovia. Por el testamento otorgado por su madre el 23 de marzo de 1523 sabemos que tuvo tres hermanas y un hermano. En AHNob, VIVERO, C.1, D.26.

${ }^{51}$ En la cuenta y partición de los bienes de María Coronel aparecen citados como Francisco y Antonio de Solís, quienes debieron nacer en 1526 y 1528, respectivamente. En AHNob, VIVERO, C. 2, D.9, fol. 5r.

52 Publicado por Peñalosa, L.F. 1949: 101-103. El documento original se encuentra en AHNob, VIVERO, C. 17, D.9.

${ }^{53}$ Ibídem, fol. $2 r$. Las siguientes frases en cursiva pertenecen al mismo folio. 
pan para cada día y un quartillo de vyno. E conplida la novena mando que se hagan las onras y se eleve de ofrenda otras quatro hanegas de trigo y dos cántaras de vyno". Y rogó que cada año se dijese en el monasterio una misa de requiem, "para la qual misa den dos velas de çera, y gastadas den otras hasta ser conplido el año".

María Coronel dispuso igualmente que en la iglesia de San Pedro de Bernardos, lugar donde la familia tenía abundantes propiedades, se dijese "un treyntanario revelado por mi ánima, para el qual se dé lo acostunbrado en el dicho logar y den la çera que fuere menester". ${ }^{54} \mathrm{Y}$ suplicó a Fadrique de Solís, su marido, y a maestre Pablo Coronel, sus testamentarios, que saldaran la deuda de ocho ducados que tenía contraída con Francisco, marido de cierta Leonor y padre de un Pedro García.

En cuanto a sus bienes, María Coronel decidió dejárselos por entero a Fadrique de Solís, con la condición de que no los pudiera vender ni enajenar. También le pidió que cuidase de todos sus hijos, incluso de los habidos en su anterior matrimonio: de hecho, le rogó que protegiese especialmente a su hijo Juan Bravo de los hermanos Sarmiento, ${ }^{55}$ "y Andresyca que la meta en un monesterio y la den allí lo que al dicho Fadrique de Solýs le pareçiere y a maestre Pablo" ${ }^{56}$ A sus otros dos hijos, Íñigo y Antonio de Solís, los mejoró en el tercio y quinto de sus bienes porque aún eran menores de edad.

Como no podía ser de otro modo, Fadrique de Solís cumplió puntualmente lo dispuesto por su esposa, sobre todo en lo relativo a la pequeña Andrea, que ingresó como doncella en el convento de religiosas franciscanas de Nuestra Señora de la Piedad de Guadalajara. Este convento había sido fundado pocos años atrás por Brianda de Mendoza, hija de Íñigo López de Mendoza, II duque del Infantado. Algunos años más tarde, Andrea Bravo de Mendoza hizo profesión de fe como monja en ese mismo convento y Fadrique de Solís la dotó con 70.000 maravedíes en metálico que provenían de su herencia materna. ${ }^{57}$ Además el convento renunció a exigir a Juan Bravo de Mendoza el resto de la legítima que pertenecía a Andrea a cambio de una obligación de pago por valor de 300.000 maravedíes en metálico. ${ }^{58}$

${ }^{54}$ Ibídem, fol. 2v.

${ }^{55}$ Francisco y Luis Sarmiento eran los hijos del segundo matrimonio de María de Mendoza, madre de Juan Bravo, y permanecieron fieles a la causa imperial durante la revolución comunera. Ambos fueron implacables enemigos de María Coronel, hasta el punto de que Francisco Sarmiento fue el encargado de secuestrar los bienes de Juan Bravo. En Peñalosa, L.F. 1949: 86.

56 AHNob, VIVERO, C.17, D.9, fol. 2v.

${ }^{57}$ AHNob, VIVERO, C.2, D. 7 . El convento otorgó carta de pago de dicha cantidad el 16 de agosto de 1546.

${ }^{58}$ AHNob, VIVERO, C.2, D.8. La renuncia se firmó en Guadalajara el 19 de septiembre de 1550. 


\section{CONCLUSIÓN}

Con la profesión de fe realizada por Andrea Bravo de Mendoza, que nominalmente no mantenía el apellido Coronel que llevaba en la sangre, se produjo la catarsis de la familia Coronel con los recientemente incorporados valores espirituales cristianos. Es muy sintomático su ingreso en un convento femenino de la ciudad de Guadalajara, bastión de la familia Mendoza y de los duques del Infantado. Quizá el poderoso linaje mendocino reclamaba emplear al nuevo vástago para estos fines, habida cuenta de que estos conventos eran fundados y patrocinados por las familias nobles con el objetivo de que se convirtiesen en reserva femenina para posteriores actuaciones clientelares del linaje. ${ }^{59}$

Los Coronel habían logrado ocultar sus orígenes judíos y permanecer en la memoria colectiva castellana de la alta modernidad. La "irresistible tendencia a conquistar un alto nivel de consideración social" 60 de esta familia judeoconversa fue la causante de la inversión económica realizada en su capilla, configurada como última morada de los miembros del linaje. Por otra parte, la familia consiguió vincularse a la alta nobleza castellana y pasar a servir a unos intereses de grupo de más amplio alcance.

La familia logró articular a través de sus testamentos un sólido mecanismo de presión sobre la institución religiosa elegida por el patrono, sobre todo de cara al mantenimiento de una actitud favorable de la misma hacia el linaje. ${ }^{61} \mathrm{Y}$ además, los testamentos sirvieron también como herramienta mediante la cual se hizo la profesión de fe que debía legitimar a sus otorgantes en una sociedad obsesionada por la limpieza de la sangre y la pureza de la fe. ${ }^{62}$

\section{APÉNDICE I \\ BIENES DEJADOS POR ÍÑIGO LÓPEZ CORONEL EN LA VILLA DE OSUNA}

El licenciado Rodrigo Blázquez, vicario de la villa de Osuna y albacea de íñigo López Coronel, pidió que se hiciese inventario de los bienes que el difunto dejó en esa villa y en sus términos. Estos fueron los bienes que se inventariaron el 1 de abril de 1522:

Una espada desguarneçida en una vayna de seda rota.

62 Jara Fuente, J.A.1996: 870-871. 
Una ropa de chamelote ${ }^{63}$ vieja aforrada en peña ${ }^{64}$ blanca.

Una loba ${ }^{65}$ de luto negra que se ha de dar a Juan de Córdova, su criado.

Un sayo senzillo de paño negro.

Una caperuça de luto negra.

Unos calçones de lana e unas xervillas ${ }^{66}$ de badana ${ }^{67}$ negras.

Unas alforjas muy viejas.

Una gualdrapa de mula de luto muy vieja rota.

Un papahígo ${ }^{68}$ de terçiopelo viejo.

Una sávana de olanda.

Otra sávana de olanda vieja traýda.

Otra sávana de lino raudada.

Dos almohadas labradas de seda negra de naval ${ }^{69}$ vasías.

Una almohada de olanda con una çínta blanca y negra.

Una toca de camino de lienço casero que dize Juan de Córdova que está enpeñada en dos reales.

Dos camisas de onbre de olanda labradas de luchuguillo. ${ }^{70}$

Otra camisa de olanda vieja rota.

Dos paños de naval de manos blancos.

Otro paño de olanda llano.

Un peynador de olanda viejo roto.

Un par de manteles alimaniscos.

Otro par de manteles de lino d'escaques. ${ }^{71}$

Otro par de manteles viejos.

Un colchón muy viejo que non vale nada.

Un repostero de lana con un escudo con çinco águilas.

Unas botas de camino viejas.

Dos espuelas de camino.

Otra espuela de rúa.

Unos pantufos ${ }^{72}$ viejos de seda.

Dos almohadas viejas.

63 Por camelote: tejido fuerte e impermeable, generalmente de lana.

64 Piel para forro o guarnición.

65 Manto o sotana.

66 Por servillas: zapato ligero y de suela muy delgada utilizado normalmente por las sirvientas.

67 Piel curtida y fina de carnero u oveja.

68 Especie de montera que cubre toda la cabeza hasta el cuello, salvo los ojos y la nariz, utilizada para defenderse del frío.

${ }^{69}$ Por morlés: tela de lino, no muy fina, fabricada en Morlés, en la región de la Bretaña francesa.

${ }^{70}$ Por lechuguilla: pieza indumentaria de tejido muy fino de color blanco, de forma rizada o escarolada, que desde comienzos del siglo XVI se utilizaba para cubrir y decorar el cuello del vestido.

${ }^{71}$ A cuadros de color, ajedrezado.

72 Por pantuflos: calzado sin orejas ni talón que se utiliza en casa para mayor comodidad. 
Una bota vieja rota e un costal viejo qués de Rodrigo Alonso, enpeñado por dos reales e medio o tres, que quedó a dever de una cuenta.

Unas escrivanías viejas con un cuchillo de almazén.

Un libro de "Oliveros de Castilla e Artur d'Algarve".

Otro libro de quentas de sus criados.

Un estera buena.

Un colchón de Ruán lleno de lana.

Una maleta de cuero de camino.

Una obligaçión en que se obligó el bachiller Gonçalo del Canpo, en nonbre de Pedro del Canpo, su padre, con su poder, de pagar a Ýñigo Lopes Coronel çiento e diez e ocho mill maravedíes.

Otras escrituras que no son de ynterese ninguno para el dicho Ýñigo Lopes que están en poder del liçençiado Rodrigo Blásquez para dallas a quien las oviere de aver, cunpliendo con él los maravedíes que monta este testamento del dicho Ýñigo Lopes.

Otras cartas mensajeras que quedaron en poder del dicho liçençiado para si oviere alguna de que se pueda aprovechar.

Un costal viejo con çinco almades (sic) ${ }^{73}$ y medio de trigo.

Un farnero ${ }^{74}$ e un medio alimur (sic).

Una mula con su silla y guarniçión de terçiopelo viejo e su freno.

Una açémila con su alvarda e aparejo.

Unas calças viejas e un jubón viejo de paño Ide grana/ e las calças negras.

Veynte ducados de oro que su señorío del conde de Urueña, nuestro señor, le hizo merçed al dicho Diego Lopes (sic), que Dios aya, al tiempo quél estava en finamiento, que los tiene Juan de Córdova.

Dixo el dicho Juan de Córdova que tenía en su poder un ducado de a dos quando su señoría le mandó dar los veynte.

Seys panezuelos ${ }^{75}$ de mesa viejos de lienço.

Un cántaro de Marchena que le dieron a la muger de Çereno.

Una fanega de alcazil ${ }^{76}$ de senbradura junto a la noria de cabe la guerta. Una sortijuela de plata que está enpeñada en medio real.

\section{APÉNDICE II ARMAS DEL APELLIDO CORONEL}

${ }^{73}$ Por almudes: unidad de medida de áridos de valor variable según las épocas y las regiones, aunque lo normal es que un almud equivalga a media fanega de sembradura.

74 ¿Por harnero?: especie de criba.

${ }^{75}$ En este caso, servilletas.

${ }^{76}$ Por alcaucil: alcachofas silvestres. 
1. Armas del apellido Coronel, según Blas de Salazar: en campo de oro, con cinco cornejas o cuervos negros. En AHNob, TORRELAGUNA, C.231, D.2, fol. 213 r.

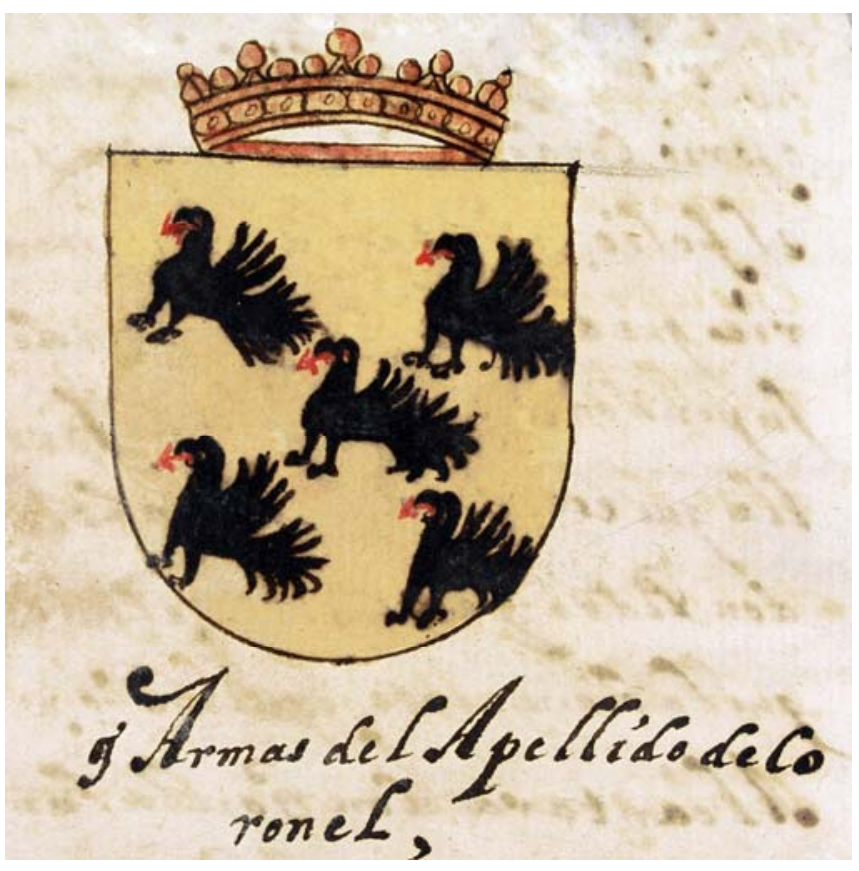

2.- Armas del apellido Coronel, según un heraldista anónimo: en campo colorado, con cinco águilas blancas. En AHNob, TORRELAGUNA, C.435, D.1, fol. $137 \mathrm{v}$.

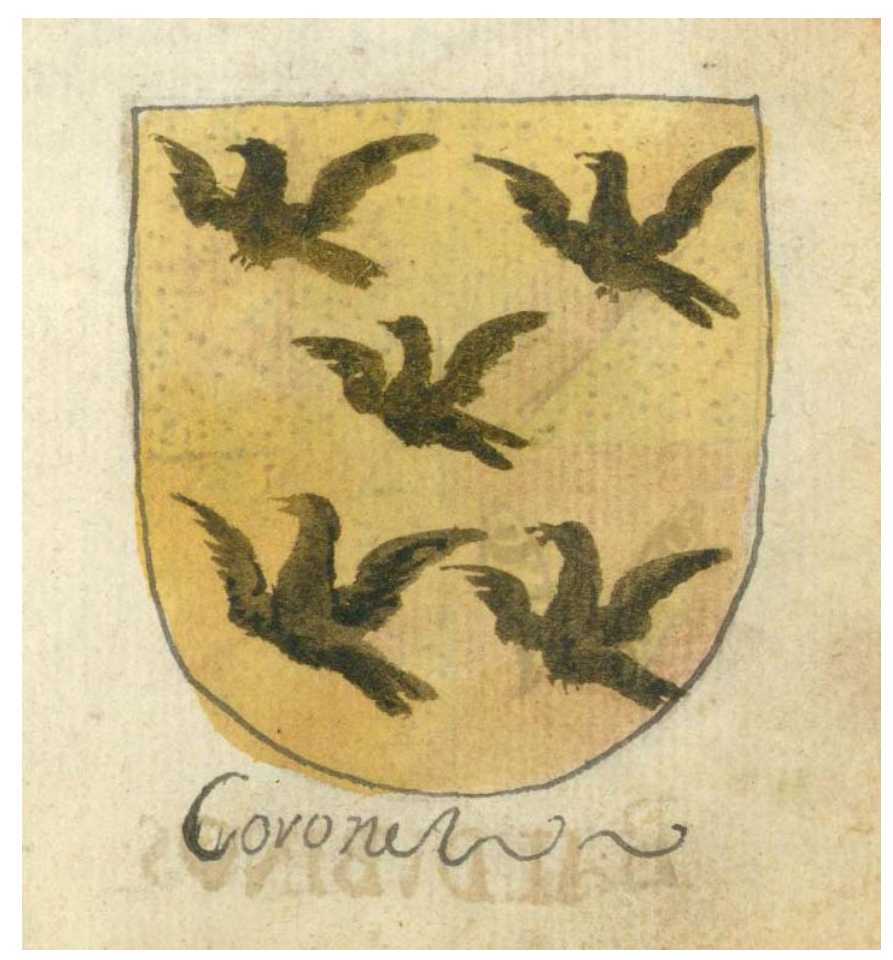


3.- Armas del apellido Coronel según el vidriero Carlos Muñoz de Pablos, que decoró con ellas la capilla familiar del monasterio de Santa María del Parral en el año 2003. El escudo trae encima el sol de la familia Solís, que se ha omitido en la fotografía. Archivo fotográfico particular.

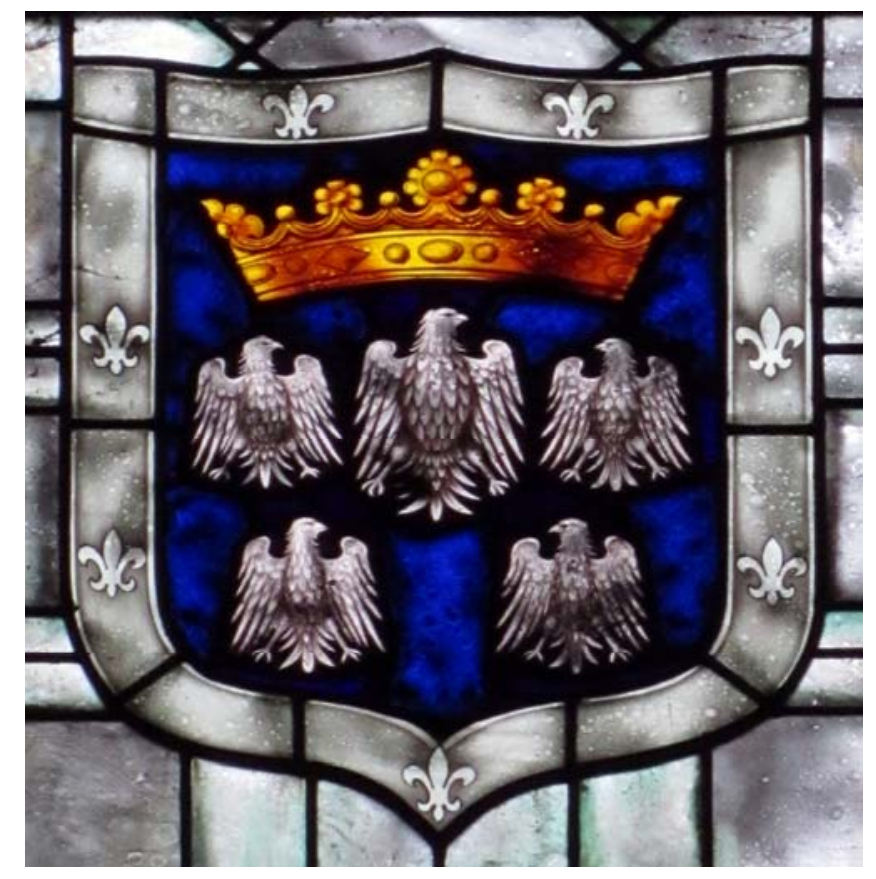

\section{APÉNDICE III LA CAPILLA DE LA FAMILIA CORONEL EN LA ACTUALIDAD}

Después de las sucesivas desamortizaciones de Mendizabal decretadas en el año 1836, el monasterio fue abandonado durante casi 90 años. En ese largo período la iglesia y sus capillas sufrieron los desmanes de los saqueadores, que se ocuparon de destrozar los sepulcros, profanar las tumbas y sustraer las laudas de bronce existentes en las capillas. $^{77}$ Los únicos restos de la familia Coronel que se conservan en el interior de la capilla son tres lápidas de los siguientes personajes:

\section{LA FIGURA DE MAESTRE PABLO}

El más conocido de ellos es maestre Pablo Coronel. Se ha sugerido que fue rabino antes de su conversión al cristianismo, ${ }^{78}$ aunque

${ }^{77}$ Agradezco a Emilio Gracia, residente en el monasterio de Santa María del Parral, las explicaciones y facilidades que me dio durante mi visita a la capilla de la familia Coronel.

${ }^{78}$ En Domínguez Ortíz, A. 1955: 162. 
lo que es seguro es que tras esta se hizo sacerdote y cursó estudios universitarios. Pablo Coronel se convertiría con el tiempo en célebre hebraísta de las universidades de Alcalá de Henares y de Salamanca. Desde 1502 colaboró en Alcalá en los trabajos de la Biblia Políglota Complutense, y veinte años más tarde se trasladó a Salamanca, donde residió hasta el momento de su muerte en octubre de $1534 .{ }^{79}$

Se desconoce la vinculación genealógica que tenía con el resto de la familia Coronel. En los testamentos de doña María Coronel, mujer de íñigo López Coronel, y de Leonor y María Coronel, sus hijas, aparece citado como "maestre Pablo", pero en ninguno se menciona su parentesco con esta rama de la familia. De hecho, ningún testimonio asegura que fuese hijo de íñigo López Coronel. Sin embargo, es sintomático que maestre Pablo fuese nombrado albacea por Leonor y María Coronel y que se hiciese enterrar en la misma capilla del monasterio del Parral en la que descansaban sus parientes. No podremos resolver esta cuestión hasta que aparezcan nuevos datos genealógicos sobre este personaje.

\section{LOS HERMANOS SOLÍS}

Los dos hermanos eran hijos de Fadrique de Solís y de María Coronel, nieta de Fernán Pérez Coronel, fundador de la capilla. Los cuerpos de ambos descansan bajo el suelo de dicha capilla:

Francisco de Solís (ca.1526-1569), cura de la iglesia de San Miguel de Segovia, falleció el 29 de enero de 1569 cuando contaba con 43 años. El escudo heráldico de su lápida trae los cinco aguilones en sotuer del apellido Coronel, y sobre la corona que remata el escudo trae un sol, figura natural del apellido Solís.

Por su parte, el doctor Antonio de Solís (ca.1528-1592) fue catedrático de Prima en leyes de la Universidad de Salamanca y murió el 18 de noviembre de 1592 a los 64 años de edad. El escudo de su lápida trae un escudo partido: $1^{\circ}$, un sol; y $2^{\circ}$, cinco aguilones puestos en sotuer.

\section{FUENTES Y BIBLIOGRAFÍA CITADAS}

Archivos

Archivo Histórico de la Nobleza (AHNob)

79 Carrete Parrondo, C. 1983. Hebraístas judeoconversos en la Universidad de Salamanca (siglos XV-XVI): 22. Salamanca: Universidad Pontificia de Salamanca. Sin embargo, en su lápida sepulcral se menciona que falleció "postrero setienbre de 1534". La lápida carece de escudo. 
- Fondo de los Marqueses de Torrelaguna

- Fondo de los Vizcondes de Altamira de Vivero

Bibliografía

Carlé, M.C. 1988. "La sociedad castellana del siglo XV en sus testamentos". Anuario de Estudios Medievales 18: 537-550.

Carlé, M.C. 1993. Una sociedad del siglo XV: los castellanos en sus testamentos. [Buenos Aires]: Instituto de Historia de España.

Carrasco Martínez, A. 2000. "Los Mendoza y lo sagrado. Piedad y símbolo religioso en la cultura nobiliaria". Cuadernos de Historia Moderna 25: 233-272.

Carrero Santamaría, E. 2001. "Patrocinio regio e Inquisición. El programa iconográfico de la Cueva de Santo Domingo, en Santa Cruz la Real de Segovia", en Actas del Congreso Internacional sobre Gil Siloe y la Escultura de su época. Burgos: Institución Fernán González y Academia Burgense de Historia y Bellas Artes: 447-462.

Carrete Parrondo, C. 1983. Hebraístas judeoconversos en la Universidad de Salamanca (siglos XV-XVI): Salamanca: Universidad Pontificia de Salamanca.

Carrete Parrondo, C. 1986. "R. Abraham Seneor (Fernán Pérez Coronel): conjeturas tradicionales y realidad documental". Sefarad 46: 111-122.

Domínguez Ortíz, A. 1991 (1 $1^{\text {a }}$ ed. 1955). La clase social de los conversos en Castilla en la Edad Moderna. Granada: Universidad de Granada.

Evans, J.A. 1998. Heresy as an agent of change. Inquisition in the Monastery of Guadalupe. Stanford University. Tesis doctoral inédita.

Frontón, M.A. 1989. "La difusión del Oliveros de Castilla: apuntes para la historia editorial de una historia caballeresca". Dicenda. Cuadernos de Filología Hispánica 8: 37-51.

Frontón, M.A.1989. "Del Olivier de Castille al Oliveros de Castilla: análisis de una adaptación caballeresca". Criticón 46: 63-76.

García Carraffa, A. y A. 1955. Diccionario heráldico y genealógico de apellidos españoles y americanos: vol. 25: Madrid.

García Casar, M.F. 2005. "Nuevas noticias sobre los SeneorCoronel segovianos", en Y. Moreno Koch y R. Izquierdo Benito (coords.), Del pasado judío en los reinos medievales hispánicos. Afinidad y distanciamiento. Cuenca, Universidad de Castilla-La Mancha: 135-146.

Gómez-Menor Fuentes, J.C. 1970. Cristianos nuevos $y$ mercaderes de Toledo. Toledo: Zocodover.

Hernández Ruiz de Villa, R. 1966. "El libro del monasterio de Santa María del Parral de Segovia. Transcripción y notas". Estudios Segovianos 18: $267-436$. 
Jara Fuente, J.A.1996. "Muerte, ceremonial y ritual funerario: procesos de cohesión intraestamental y de control social en la alta aristocracia del Antiguo Régimen (Corona de Castilla, siglos XV-XVIII)". Hispania 194: 861-883.

Ladero Quesada, M.A. 1998. Los señores de Andalucía. Investigaciones sobre nobles y señoríos en los siglos XIII a XV. Cádiz: Universidad de Cádiz.

Ladero Quesada, M.A. 2003. "Coronel, 1492: de la aristocracia judía a la nobleza cristiana en la España de los Reyes Católicos". Boletín de la Real Academia de la Historia 200/1: 11-24.

Martínez Meléndez, M.C. 1989. Los nombres de tejidos en castellano medieval: Granada: Universidad de Granada

Ortego Rico, P. 2008. "El patrocinio religioso de los Mendoza: siglos XIV y XV". En la España Medieval 31: 275-308.

Peñalosa, L.F. 1949. "Juan Bravo y la familia Coronel". Estudios Segovianos 1: 73-109.

Rábade Obradó, M.P. 2002. "Mecenazgo religioso y estrategias familiares en la Segovia del siglo XV: Diego Arias Dávila y el Hospital de San Antonio". Anuario de Estudios Medievales 32/2: 915-947. 